\title{
Air Preheater Temperature Analyses on Notched Flat Elementusing CFD
}

\author{
$\mathrm{S} \mathrm{Babu}^{1}$, DhinakaranV ${ }^{2}$, KeerthiVaasan Rajagopal ${ }^{3}$, M. Govindaraj ${ }^{4}$ \\ \{sjsham@gmail.com ${ }^{1}$, dhinakaran.veeman@gmail.com², aasan2971999@gmail.com³ \\ govindarajm.sh@krct.ac.in ${ }^{4}$ \}
}

Associate Professor, Department of Mechanical Engineering, PSG College of Technology, Coimbatore $^{1}$, Professor,Chennai Institute of Technology, Chennai ${ }^{2}$, Scholar, AMRITA University, Coimbatore $^{3}$, Department of Chemistry, K.Ramakrishnan College of Technology, Tiruchirappalli ${ }^{4}$

\begin{abstract}
In an Industrial process the heat that is not used effectively and lost as waste.This is considered as waste heat energy and dumped into the environment. Reusing the waste heat can be done by various recovery techniques, one such system is the Air Pre-Heating system (APH) [1].This could be used as a valuable energy source and thereby reduce the overall energy consumption. An improvised approach for recycling waste heat energy is presented here. In this paper, a performance comparison was made using various heat elements for the rotor regenerator in Heavy Industry. The results reveal that the rectangular vortex generator is the best option for heat recovery in an APH system.
\end{abstract}

Keywords: CFD, Air pre-heating, Notched flat element,Temperature distribution study.

\section{Introduction}

Thermal Power Plant's overall efficiency can be increased by introducing preheated air before it enters the combustion chamber [1]. In primitive power plants the air for combustion is not pre-heated, to bring the required temperature suitable for combustion, more energy is required to heat to the required temperature .there is an increase in fuel consumption and the overall cost thus decreasing the efficiency of the plant. We propose a Rotary regenerator Air Pre-Heater (APH) (Ljungstrom) system to preheat the air supply at an industrial level. Performance Parameters such as reliability, effective leakage control, and its adaptability to burn almost any fuel were proved to be better with durable service over a long period. Simple design makes it more easy operable and economic. Energy conservation is obtained by the waste heat energy in this industrial process. For every 40 to 50 degree $\mathrm{F}$ increase in combustion air temperature, Ljungstrong APH saves about 1-11/2 \% of fuel. As a result, the plant will provide consistent service throughout its life. Heat energy is collected and transferred to incoming air for burning, resulting in long-term fuel savings.

Existing system: A rotary regenerator is made out of a centre rotor that rotates at a steady speed. The heat transfer surface attached to the rotor's centre collects heat from the exhaust hot gas and transmits it to the entering cold air, converting the system to a pre-heater. This surface is also known as the Matrix. The APH is divided into two sectors[2, 10]. This cycle keeps repeating as long as the plant is in operation. The flat metal matrix experience thermal fatigue stress due to temperature difference between heating and cooling cycles which affect the 
overall efficiency. We propose the following alternative techniques for thermal fatigue monitoring.

Notched flat element:This problem is overcome by using Cor-Ten high strength low alloy steels with enhanced corrosion resistance for the Cold End heating elements. With a 2\% investment in modern boilers, can return up to $20 \%$ heat output into the process. A Notched Flat (NF) Element is introduced for Cold End Heating element. Despite its low thermal efficiency, NF's wide-open design makes it suitable for use at the Cold End of coal-fired plants, where condensation mixes with ash to cause corrosion and clogging. [3] Formalized paraphrase they use thicker gauge steel for longer life and resistance to corrosion.

\section{Background Of The Research Work}

Air Pre-heater (APH) is important equipment in modern Thermal Power Stations as shown in Fig.1. The type of air Pre-heater dominating the Power Plant segment is the regenerative type, first and foremost because it is extremely efficient which results in reduced space requirements and a lower price.

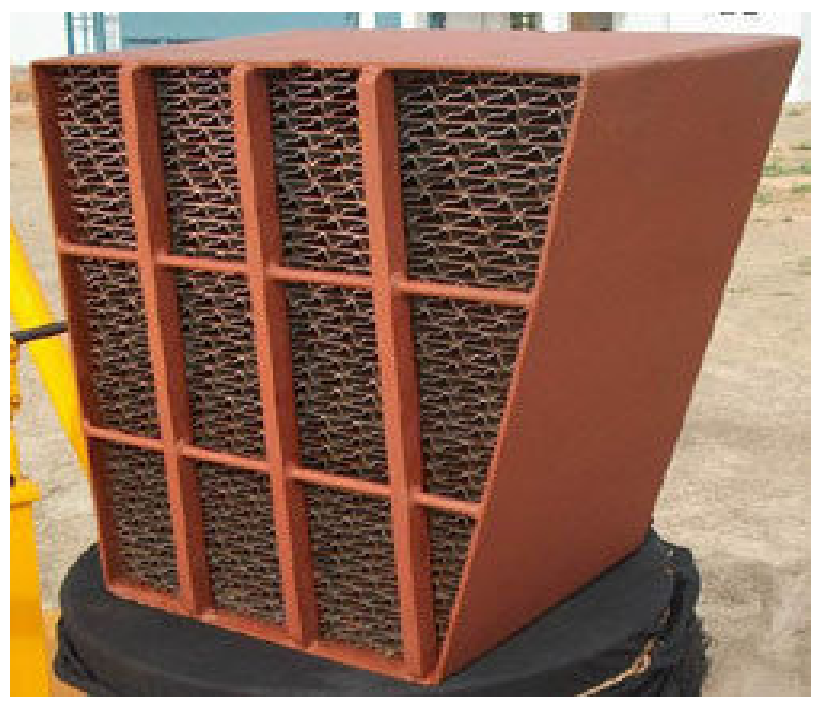

Fig 1: Air Pre-Heater

Heat Transfer Elements: Because the heat transmission element is the core of the air Pre-heater, it is critical that thermal and hydrodynamic data be trustworthy.Apart from the existing flat notch type, there are four other heat transfer elements with different geometry and profiles are considered for analysis [4].All of the elements' performance has been evaluated in labs.

Flat Notched Crossed: This type of heating element has the best thermal performance, which results in the shallowest heater for a given thermal duty [5]. Furthermore, because the pressure drop per unit of heat transmission is smaller than for any other element, it will have the lowest pressure drop. 
Double Undulated Element: The DU (Double Undulated) is a Series of hot and intermediate layer element has been the most preferable in the air Pre heater industry. Air Systems manufactures the full range of DU elements including the standard DU 2.9-2.5. as shown in Fig.2. The DU element is distinguished by the alternate stacking of "Undulated" element sheets with both undulations and notches. These elements are mainly used for hot and intermediate layers of baskets. This element substitutes the FNC element when the fuel ash is predicted to be more erosive than usual or where fouling is more likely, such as at the cold end. This is due to the fact that a) the gas is less turbulent as it passes past the element, resulting in less erosion. (b) Because the passageways through the element tend to keep the energy of the air or steam utilised in soot blowing from dispersing, cleaning efficiency is maintained over the whole length of the tier [6].

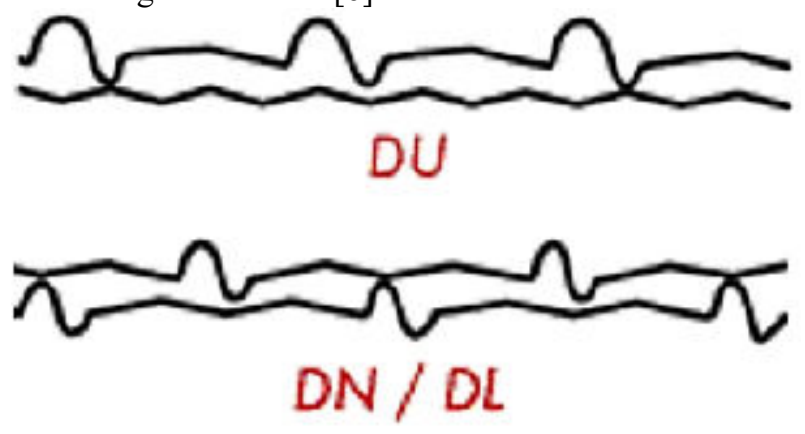

Fig 2: DU Series Element

CU - Corrugated Undulated: A more open element than DU, but it requires a higher depth and therefore pressure drop to achieve the same heat transfer as illustrated in Fig.3. It also features a profile, which aids in cleaning efficiency.

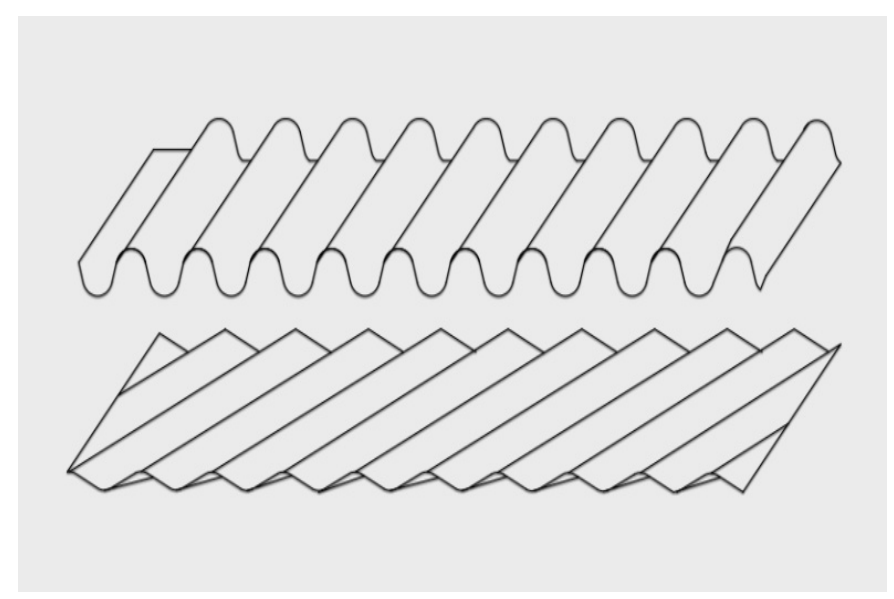

Fig 3: CU Element

NOTCHED PLATE: The most basic element now in use, its poor heat transmission characteristics, which result in a deep rotor, imply that it is rarely employed anymore. 


\section{CFD Simulation}

The existing model of one pitch of the air preheater heating elements is shown in Fig. 4.with its geometry.It is made up of CORTEN steel. The heating element is a Notched Flat (NF) heating element, widely used in Ljungstorm air pre-heater. Also, it is used in both static and rotary regenerator [8 and 10$]$.

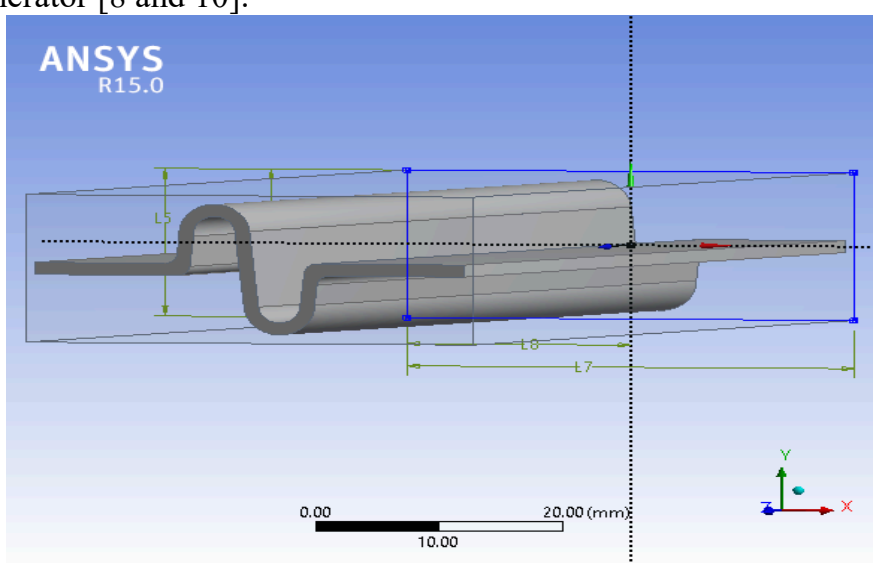

Figure 4 Geometry of Existing Model

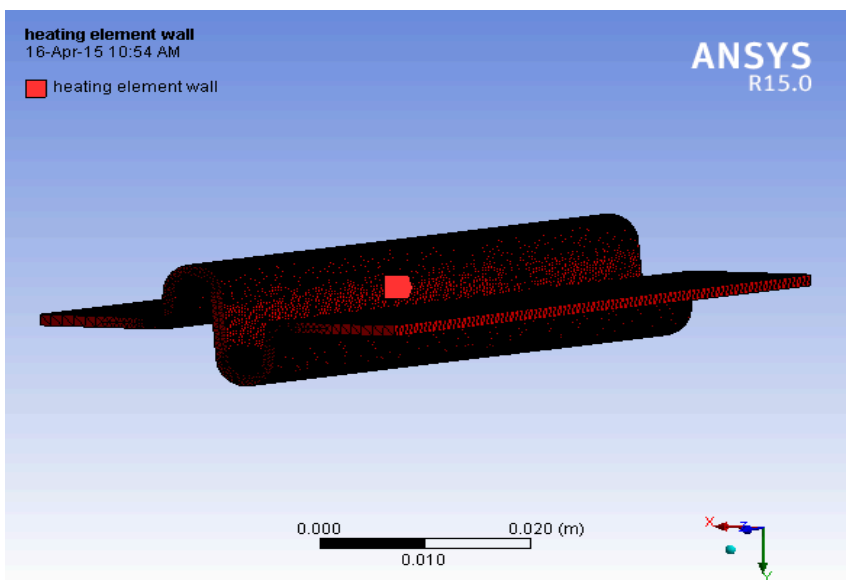

Figure 5Mesh of the Existing Model

The geometry was created using ANSYS geometry is shown in Fig. 5. The specifications were as mentioned below: The thickness of the plate is $1.214 \mathrm{~mm}$ and its length was taken as $100 \mathrm{~mm}$ for analysis. The mesh was done after creating the geometry.There are around 7,00,000 elements (both solid and fluid) in the meshed geometry. The fluid here used is air. Inflation was given to all edges of the geometry with maximum of 5 layers [7]. 


\section{Results And Discussion}

A three-dimensional modelis developed to investigate flow and heat transfer rates on existing and modified notch elements. A series of numerical calculations have been conducted by FLUENT and the results are presented with the effects the on velocity of heat flow,static pressure and temperature distribution with concerning to the obtained Reynolds number[3].

Static Pressure Temperature and Velocity Study: Cycles and the iteration graph are given below in Fig.6-8.

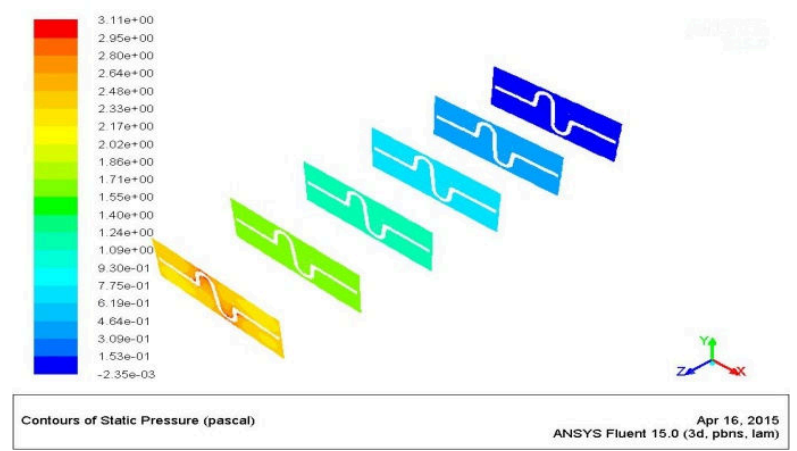

Fig 6 - Contour of Static Pressure @ Re=2300 for Existing Model

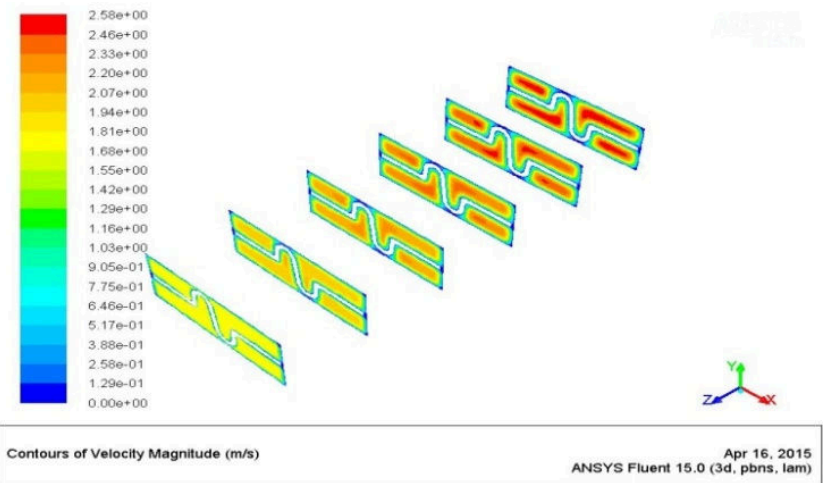

Fig 7 - Contour of Velocity @ Re=2300 for Existing Model

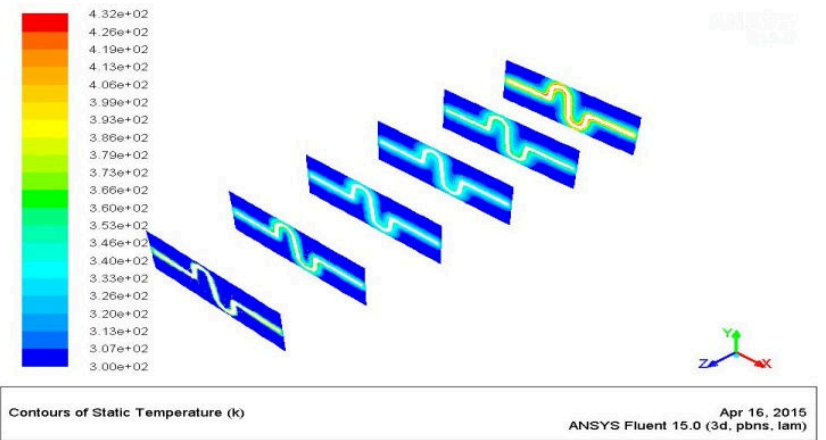

Fig 8 - Contour of Temperature @ Re=2300 for Existing Model 


\section{Conclusions}

- The computational simulations using CFD- Fluent was carried out by passing the air over heat transfer elements (heating plates) with various configurations such as rectangular vortex generator, trapezoidal vortex generator, isosceles triangular vortex generator and inward line right angle triangle vortex generator.

- For the rectangular type vortex generator, the performance ratio maximum when compared with other types of vortex generator, surface heat transfer coefficient also maximum for this and it is equal with isosceles triangle vortex generator. The pressure drop is less for various inlet conditions and flow when compared to other configurations. At $R e=8000$, it is obtaining reasonable exit temperature and enthalpy also high.

Further the same can be extended using Electro,Optical and Nano-sensors to enhance the outcomes.

\section{References}

[1] He, Y. L., Han, H., Tao, W. Q., \& Zhang, Y. W. (2012). Numerical study of heat-transfer enhancement by punched winglet-type vortex generator arrays in fin-and-tube heat exchangers. International Journal of Heat and Mass Transfer, 55(21-22), 5449-5458.

[2] Leu, J. S., Wu, Y. H., \& Jang, J. Y. (2004). Heat transfer and fluid flow analysis in plate-fin and tube heat exchangers with a pair of block shape vortex generators. International Journal of Heat and Mass Transfer, 47(19-20), 4327-4338.

[3] Torii, K., Kwak, K. M., \& Nishino, K. (2002). Heat transfer enhancement accompanying pressureloss reduction with winglet-type vortex generators for fin-tube heat exchangers. International Journal of Heat and Mass Transfer, 45(18), 3795-3801.

[4] McDonald, C. F. (2003). Recuperator considerations for future higher efficiency microturbines. Applied Thermal Engineering, 23(12), 1463-1487.

[5] Aquaro, D., \&Pieve, M. (2007). High temperature heat exchangers for power plants: Performance of advanced metallic recuperators. Applied Thermal Engineering, 27(2-3), 389-400.

[6] Zhang, L., \&Che, D. (2012). An Experimental and Numerical Investigation on the ThermalHydraulic Performance of Double Notched Plate. Journal of Heat Transfer, 134(9), 091802.

[7] Jouhara, H., Khordehgah, N., Almahmoud, S., Delpech, B., Chauhan, A., \&Tassou, S. A. (2018). Waste heat recovery technologies and applications. Thermal Science and Engineering Progress, 6, 268-289.

[8] Babu S, Paul Gregory F, Nirmal Kumar TV, KasiAswin K, Manisekar, K and Ilango, K, (2018) Heat Distribution Studies on Slewing Ring Bearings using FLOTHERM Software,IEEE Xplore, 978-1-5386-4021-0.

[9] Babu S, Manisekar K, Kalaiselvi S (2017), 'Heat Transfer Analysis of Slewing Ring Bearing for High Thermal Applications', ASME Journal of Thermal Science And Engineering Applications, MARCH 2017, Vol. 9, PP: 011006-9, 1948-5085.

[10] Babu S, Prabhu T, Arjun V S, SaiPhanendra G, and Eswar Chandra Y, (2017) ‘CFD Analysis of a Thermal-Mixer for Solar Concentrated Air Heater', International Journal of Control Theory and Applications, Vol. 10/28, PP: 73-83, 0974-5572.

[11] C. Amuthadevi, D. S. Vijayan, Varatharajan Ramachandran, "Development of air quality monitoring (AQM) models using different machine learning approaches", Journal of Ambient Intelligence and Humanized Computing, https://doi.org/10.1007/s12652-020-02724-2

[12] M. Tholkapiyan, A.Mohan, Vijayan.D.S , "A survey of recent studieson chlorophyll variation in Indian coastal waters", IOP Conf. Series: Materials Science and Engineering 993 (2020) 012041, doi:10.1088/1757-899X/993/1/012041.

[13] Kiruthika, C., S. Lavanya Prabha, and M. Neelamegam. "Different aspects of polyester polymer concrete for sustainable construction." Materials Today: Proceedings 43 (2021): 1622-1625. 